\title{
REALIDADE VIRTUAL COMO TECNOLOGIA DE APOIO AO PROCESSO DE EDUCAÇÃO INCLUSIVA PARA DEFICIENTES INTELECTUAIS
}

\author{
Daniel F. P. de Vasconcelos*, Yuran C. Dias*, Gabriel C. Araújo*, Edgard A. Lamounier Jr* e \\ Fernanda F. O. Malaquias** \\ * Universidade Federal de Uberlândia, Faculdade de Engenharia Elétrica, Uberlândia/MG, Brasil \\ ** Universidade Federal de Uberlândia, Faculdade de Gestão e Negócios, Uberlândia/MG, Brasil
}

E-mail: danielvasconcelos@ufu.br

\begin{abstract}
Resumo: Esta pesquisa tem como principal objetivo explorar o uso da Realidade Virtual como tecnologia de apoio à Educação Inclusiva, por meio do desenvolvimento de um jogo em ambiente virtual de ensino-aprendizagem para alunos com deficiência intelectual. Para isso, serão identificadas, junto a professores e profissionais especializados, as necessidades educacionais e principais limitações dos alunos com deficiência intelectual. Após o desenvolvimento e modelagem do ambiente virtual, que será voltado para atender as necessidades específicas dos alunos, o mesmo será utilizado com esses alunos matriculados em Escolas Inclusivas.
\end{abstract}

Palavras-chave: Realidade Virtual, Jogo Sério, Deficiência Intelectual, Educação Inclusiva.

\begin{abstract}
This research aims to explore the use of virtual reality technology to support inclusive education, through the development of a game in the teaching-learning virtual environment for students with intellectual disabilities. For this, they will be identified, with teachers and professionals, educational needs and main limitations of students with intellectual disabilities. After the development and modeling of virtual environment, which will be turned to meet the specific needs of students, it will be used with these students enrolled in Inclusive Schools.
\end{abstract}

Keywords: Virtual Reality, Serious Game, Intellectual Disability, Inclusive Education.

\section{Introdução}

A educação inclusiva tem se tornado tendência, em um contexto mundial, em que vários tópicos sobre este assunto têm sido discutidos. Em vários países, as escolas têm enfrentado desafios no desenvolvimento de uma pedagogia capaz de educar a todos os alunos com êxito, independente de condições físicas, intelectuais, emocionais e linguísticas [1].

No cenário brasileiro, o Ministério da Educação tem feito esforços para implementar vários programas com objetivo de promover políticas de inclusão em sistemas educacionais nos municípios, a fim de ampliar as possibilidades de aprendizagem a todos os alunos.
Segundo o Censo Escolar MEC/INEP, houve crescimento expressivo em relação às matrículas de alunos com deficiência na educação básica regular. Os dados indicam que no ano de 2014, 698.768 estudantes especiais estavam matriculados em classes comuns [2].

Os ambientes virtuais proporcionam às pessoas com necessidades especiais a possibilidade de interação de forma realista e segura em situações que seriam inacessíveis para elas, devido suas limitações cognitivas, motoras ou psicológicas [3]. Assim, a Realidade Virtual pode ser usada para o auxílio na recuperação e reabilitação de funções motoras, podendo também ser utilizada por pessoas com deficiências permanentes.

Além disso, a Realidade Virtual é uma área tipicamente multidisciplinar, envolvendo conceitos que tem origem de diversos segmentos, com aplicação em múltiplas áreas e campos específicos da área econômica, social e cultural. Por possibilitar uma interação humanocomputador de forma mais natural e prover a reprodução de situações reais, essa tecnologia tem amplo potencial de uso [4], inclusive na área da educação especial.

\section{Materiais e métodos}

Primeiramente, pretende-se identificar as necessidades dos alunos com deficiência intelectual, juntamente com professores e profissionais especializados, com vista ao entendimento das necessidades educacionais especiais e principais limitações dos alunos com o tipo de deficiência já especificado.

Após isso, será possível a elaboração de um instrumento de coleta de dados, um questionário, para ser aplicado aos professores das escolas selecionadas. Este questionário será aplicado em duas etapas: a primeira antes do uso do ambiente virtual desenvolvido e a segunda após o seu uso. A elaboração consistirá em questionários de avaliação, com base nas necessidades identificadas no último tópico.

Concomitantemente, será concluída a modelagem do cenário 3D e, após isso, o desenvolvimento do ambiente virtual, com os objetos e acessórios que foram 
modelados. Para essa modelagem está sendo utilizado o software Autodesk 3ds Max 2016 e o ambiente virtual será desenvolvido no software Unity 3D - versão 5.2.2f1.

Narrativa do jogo - Para que o jogo cumpra com seus propósitos de desenvolvimento dos alunos com deficiência intelectual, a narrativa do jogo foi elaborada com tarefas e atividades que farão com que esses alunos interajam de tal forma que associarão os objetos do ambiente virtual com os objetos reais. Assim, o jogador estará no ambiente de uma casa (quarto e cozinha), onde a primeira tarefa consistirá em arrumar a mochila para um piquenique no parque. Para isso, ele deverá selecionar os objetos solicitados, dentre eles roupas, brinquedos, produtos de higiene pessoal, comidas e bebidas. A segunda tarefa se consiste em adquirir os objetos que deverão ser levados ao piquenique, mas não estão na casa, devendo ser comprados no ambiente do shopping. Após possuir todos os objetos necessários, a última atividade é participar do piquenique no ambiente do parque.

A avaliação dos benefícios aos alunos com deficiência intelectual, referentes ao uso do Ambiente Virtual, dar-se-á por meio da aplicação de questionários sobre os alunos aos professores. Nesta etapa, antes da utilização do jogo, serão aplicados questionários aos professores buscando estimar as habilidades e conhecimentos sobre os conteúdos trabalhados com o sistema, de cada um dos alunos. Após a utilização do jogo, os questionários são novamente respondidos pelos professores (sem consulta ao primeiro questionário aplicado), em que os resultados permitirão constatar o comportamento do nível de conhecimento e habilidades dos alunos antes e depois do uso do jogo.

Feita a primeira aplicação do questionário, será iniciada a utilização do jogo desenvolvido com alunos público-alvo da pesquisa, matriculados em Escolas Inclusivas. Nesta etapa, o software será utilizado com os alunos durante o período de três meses, com a frequência de uma vez por semana. A aplicação do software será completamente acompanhada por um pesquisador do projeto, além de dispor de um roteiro de orientações de atividades e resultados esperados, o que possibilitará um auxílio na interação do professor com o aluno e do aluno com o software.

Após os três meses da utilização do jogo pelos alunos, o questionário sobre cada um deles será novamente aplicado aos professores, permitindo estimar suas habilidades e conhecimentos relacionados aos conteúdos explorados por meio do software. A comparação das respostas dos questionários antes e após o uso do Ambiente Virtual será formalizada por meio do teste $t$ de diferença para médias, considerando-se, para isso, amostras pareadas [5]. O objetivo deste procedimento permitirá a avaliação se as habilidades e conhecimentos dos alunos apresentaram aumento estatisticamente significativo após a utilização do jogo. Estas diferenças serão calculas por aluno (para as diferentes habilidades) e por habilidade (para diferentes alunos).
A avaliação dos resultados provenientes do uso do Ambiente Virtual será pautada também na análise qualitativa, que será desenvolvida com base na observação sistemática e entrevistas semiestruturadas com os professores envolvidos na aplicação e uso do software. Nesta etapa poderão ser evidenciadas especificidades em seu uso, formas de otimização de sua aplicação, além de particularidades no processo de interação entre os atores envolvidos (papel dos alunos, papel dos professores e papel dos pesquisadores). Caso o ambiente virtual obtenha indicadores adequados de contribuição significativa para o nível de aprendizado dos alunos, o mesmo será disponibilizado gratuitamente na Internet para todos os interessados.

O projeto obteve parecer favorável do Comitê de Ética, número de aprovação 878.279, no dia 19/11/2014.

\section{Resultados}

Para este projeto, a modelagem dos objetos foi feita no Autodesk 3ds Max 2016. Os objetos já modelados são os brinquedos, alimentos e roupas. Assim, os resultados preliminares dessa modelagem serão apresentados na seção a seguir. Os principais resultados esperados, impactos e benefícios para a sociedade serão detalhados em uma seção denominada por resultados futuros.

Resultados Preliminares - Como resultados preliminares, tem-se a modelagem dos objetos $3 \mathrm{D}$ que serão utilizados no ambiente virtual. Para ilustração e exemplo dos objetos, as figuras 1, 2 e 3 representam as categorias denominadas por "brinquedos", "roupas" e "alimentos" respectivamente. Além dessas categorias, há também a categoria "higiene pessoal", cujos objetos estão em fase de modelagem.

A Figura 1 é o modelo desenvolvido de uma bola de vôlei, da categoria "brinquedos".

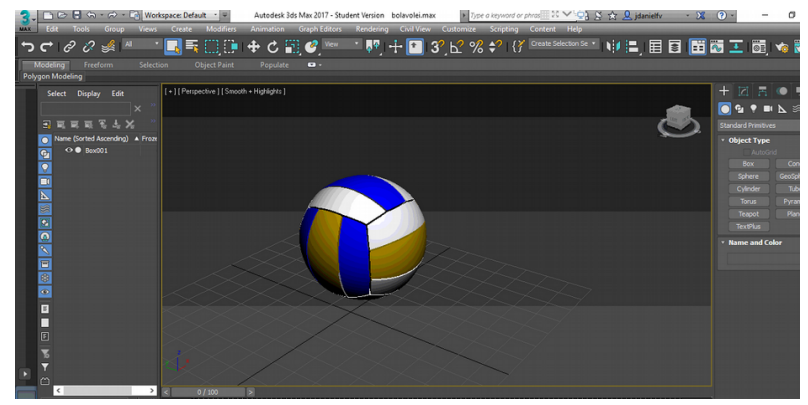

Figura 1: Bola modelada no Autodesk 3ds Max 2016.

A Figura 2 é o modelo desenvolvido de um boné, da categoria "roupas". 


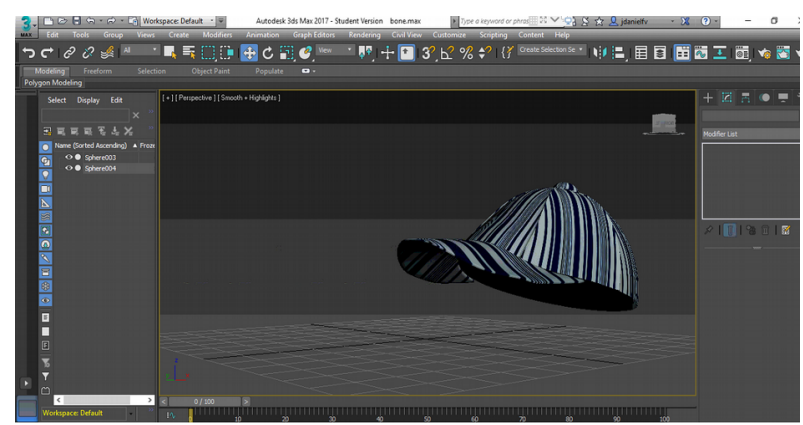

Figura 2: Boné modelado no Autodesk 3ds Max 2016.

A Figura 3 é o modelo desenvolvido de um bolo, da categoria "alimentos".

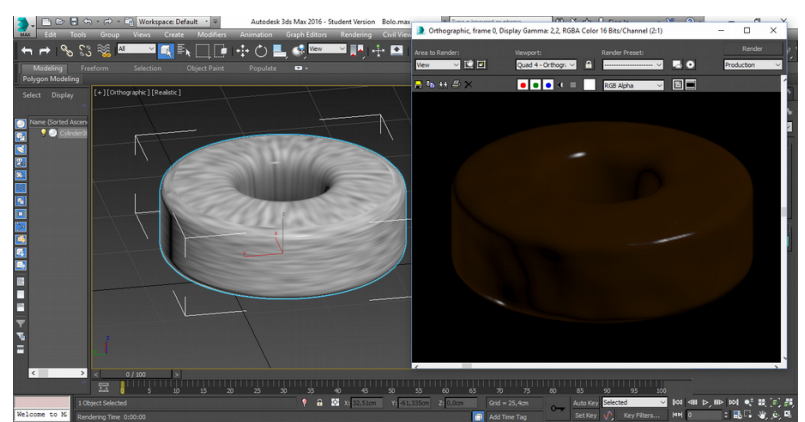

Figura 3: Bolo modelado no Autodesk 3ds Max 2016.

Resultados futuros - Após o desenvolvimento do jogo e sua aplicação conforme descrita em Materiais $e$ métodos, são esperados alguns resultados deste projeto.

Com a execução desse trabalho, pretende-se contribuir com o processo de Educação Inclusiva, tanto em Uberlândia/MG, quanto em outras regiões, apoiando os professores, no sentido de encontrar soluções para minimizar as limitações dos alunos com deficiência. Espera-se então, que as tecnologias a serem desenvolvidas possam contribuir de forma singular com o processo de ensino-aprendizagem de tais alunos, facilitando a aprendizagem de conteúdos que por motivos diversos, não são aprendidos por eles na forma convencional de ensino.

Como contribuição científica, destaca-se a realização de estudos com testes empíricos sobre a aplicação da Realidade Virtual em contextos diferentes dos já explorados, contribuindo com o avanço das pesquisas e aplicações dessa tecnologia neste assunto.

Por fim, ressalta-se que um dos diferenciais da proposta apresentada nesse projeto é o objetivo de disponibilizar gratuitamente na Internet, as ferramentas que dele resultarem. Dessa forma, alunos e professores de Minas Gerais e de todo o país poderão usufruir dos possíveis benefícios deste jogo de ambiente virtual.

\section{Conclusão}

Este projeto tem como objetivo principal explorar o uso da Realidade Virtual como tecnologia de apoio à Educação Inclusiva, em específico para alunos com deficiência intelectual, por meio do desenvolvimento de um jogo sério. Espera-se que os resultados sejam de uma nova ferramenta que contribuirá para uma melhor aprendizagem de crianças que não tem as mesmas condições de aprender com as técnicas convencionais de ensino, avançando nos estudos de como a Realidade Virtual pode contribuir na área da Educação Inclusiva e da saúde em geral.

\section{Agradecimentos}

Os autores deste trabalho agradecem à Fundação de Pesquisa do Estado de Minas Gerais (FAPEMIG) pela confiança, apoio e amparo financeiro, sem os quais não seria possível a realização desse trabalho. Ao Laboratório de Engenharia Biomédica (BioLab FEELT/UFU) e ao Laboratório de Computação Gráfica (LabCG - FEELT/UFU) pelo amparo tecnológico e estrutural para a realização desse trabalho.

\section{Referências}

[1] SÁNCHEZ, P. A. A Educação Inclusiva: um meio de construir escolas para todos no século XXI. [S.1.]: INCLUSÃO - Revista da Educação Especial, 2005..

[2] BRASIL. Dados do Censo Escolar indicam aumento de matrícula de alunos com deficiência. 2015. D i s p o níve 1 e $\mathrm{m}$ : $<$ http://www.brasil.gov.br/educacao/2015/03/dadosdo-censo-escolar-indicam-aumento-de-matriculasde-alunos-com-deficiencia>. Acesso em: $10 \mathrm{fev}$. 2016.

[3] SCHULTHEIS, M. T.; RIZZO, A. A. The application of Virtual Reality technology in Rehabilitation. [S.1.]: Rehabilitation Psychology, 2001. p. 296-311.

[4] MACHADO, L.; MORAES, R. M.; NUNES, F. L. S. Abordagens práticas de realidade virtual e aumentada. XI Symposium on Virtual and Augmented Reality, 2009.

[5] ANDERSON, D. R.; SWEENEY, D. J.; WILliAMS, T. A. Estatística Aplicada à Administração e Economia. $2^{\mathrm{a}}$ ed.. São Paulo: Cengage Learning, 2007. 